\title{
Research on the Framework of High-Tech Terrace Based on High-Tech Industry*
}

\author{
Jie Chen ${ }^{1,2}$, Jiayi Yao ${ }^{1}$, Tao Wang ${ }^{2}$ \\ ${ }^{1}$ School of Economics and Management, Beijing Jiaotong University,Beijing, China \\ ${ }^{2}$ Beijing KM Consullting CO., LTD., Beijing, China \\ mumu_muma@163.com,jyyao@bjtu.edu.cn,wangtao@gei.com.cn
}

\begin{abstract}
Nowadays, the High-Tech develop rapidly, the industrial clusters have been the important carrier to the economic development in our country, as well as the integrated form of science and technology service has been the objective needs to Chinese characteristic industry clusters entering into the period of strategic transformation. However, there is a lack of an integrated platform to gather, integrate, participation the scientific and technological resources which are growing day by day. Therefore, analyzing the framework of NISP, researching on the science and technology service, so that we can achieve the construction project of the HighTech Terrace, and we can also summarize some characters of the High-Tech Terrace when the terrace is being constructed. We are always are obliged to pay much attention to these characters, such as open, serviceability, synergy and so on.
\end{abstract}

Index Terms - science and technology service industry; HighTech Terrace, Framework, construction of platform.

\section{Introduction}

Technology service in our country has begun to take shape, and there are a group of stronger service agencies. Great effort should be given to developing science and technology service, for the reason that it is not only the objective requirements of our country's characteristic industrial cluster entering into the strategic transition, but also the strategic needs of our country's Science and Technology service industry realizing resources integration, exploring mode innovation, and it's the effective measures for the science and technology service to improving the credibility level and the quality, too. In 2007, the state council put forward in the document, which is about the several opinions about speeding up the development of service industry, that "great effort should be given to developing law service, and the role of science in leading and supporting the development of service industry should be given full play, and great efforts should be made to encourage the specialized service industry, such as technical research and development, technology extension, industrial design and energy conservation". After years of development, the science and technology service industry in our country has a good base for development, formed the pattern of industry that $\mathrm{R} \& \mathrm{D}$, design, technology transfer, start a business and industrialization, science and technology Financial, science and technology consulting as the main body, the public institutions and private institutions complement each other and communal development.

\footnotetext{
${ }^{*}$ National science and technology support project(2012BAH25F01)
}

However, many problems exist, such as unable to make science and technology resources sharing, science and technology resources are monopolized and scattered, and the existing resources, including enterprises, knowledge resources, equipment resources, statistics resources, can't be fully integration and system optimization, due to the lack of an integration platform of science and technology service industry service.

\section{Present Situation of Science and Technology Services}

(1) Technology service in our country has begun to take shape, and there are a group of stronger service agencies. Integrated technology services have been the strategic needs of China's service industry to speeding up the resources integration of science and technology, cultivating industry leading, exploring mode innovation.

(2) The science and technology services quality is lack of the evaluation standard of standardization, normalization. Science and technology services is intellectual services, so that the quality and effectiveness of the deliverables are difficult to measure; Science and technology services industry has not yet set up standardized service process and evaluation index, and each service credibility also lack of common standards. The difficulty for the Demand Siders to estimate which service agencies to choose has indirect increased. At present, there is no effective way for technology services to cluster technology service, provide a unified, standardized, modular service products to the demand side.

(3) The resources of science and technology services are asymmetric. There is information asymmetry in the aspect of service demand and service deliverables between the industry cluster and the enterprises in the cluster and the science and technology services, so that he difficulty of service effective link between demand and supply has increased, and the cost of technology service transaction is very high.

(4) Science and technology service lack of integrated service pattern. Compares with the international science and technology service agencies in developed countries, such as McKinsey, Accenture, the science and technology service agencies in our country exist flaw that average size is smaller, integration of comprehensive service ability is weaker, service channels are single, so that they can't afford comprehensive 
service requirements for the enterprises in the industrial cluster.

Therefore, there is an urgent need to construct a scientific service integration platform oriented to a high and new technology industry cluster, to provide integrated services, promote science and technology resources sharing, dock the supply and demand, promote service, improve the service level and quality, reduce the transaction costs and improve the trade efficiency.

\section{The Framework of Science and Technology Service Integration Platform}

\subsection{Summary of Service Integration Platform of Science and Technology}

Service integration platform is the important foundation of scientific and technological innovation, with the goal that gather the social science resources to form the open and Shared terminal services carrier, using modern tools such as information networks, combining with colleges universities, research institutes, enterprises and government departments and any other subject, strategic restructure and optimize the collection of the science and technology resources, constantly promote the service system which comprehensively utilized and effectively integrated the social science resources.

\subsection{The Framework of Science and Technology Service Integration Platform}

Take Shanghai's research and development of public service platform[2]for example, the overall operation process involves four major sections including "portal", "integrated management system", "synergistic network", and "service", the function of each part is respectively as follows: "portal" is distribution window of the science and technology resources which provides service for the user's navigation, online query and customization; "Integrated management system" is the hub of platform, responsible for the allocation and management of the subsystems' resources of the platform; "Synergistic network" consisted of every subsystem of the platform and relevant service organization, can realize the linkage of the multi-level services and distributed service support.

In addition, this paper also analysed the platform architecture such as site group ${ }^{[3]}$, and according to the technology service's feature of intensive knowledge, community service innovation driving and the collective resources, designed the business framework of technology service integration, and analysed the function of each subsystem.

The integration platform of Science and technology service includes a web portal and six subsystems:

Portal is the distribution window of science and technology resources which support the search and display services of framework and service product, interactive online community, and provide service trade entry, etc.

Service resource relationship network subsystem help enterprises or services build their own management center, such as service product release, service demand docking, agency information maintenance, consulting, project management, customer relationship management, etc.

Industrial cluster database subsystem promote industrial clusters and attract enterprise and service institute for them by update maintenance of the industrial cluster data.

Service trade subsystem help users build an online service, provide the online trading and statistical analysis, assist service agencies to manage transactions including service trade management, all the service credit evaluation, interests sharing, etc.

Knowledge resources subsystem enlarge the influence of service agencies by managing and distributing the knowledge, which mainly provide three modules including the knowledge management, knowledge base and knowledge base of industrial cluster.

Project's online collaboration space develops project's online management and interaction, enhances the communication with customers, assists in effective online project management services, such as providing consulting project standard management, cooperative research on project management, service support, integrated the whole contractor project management, etc.

Platform management subsystem is a Unified Management Platform which can help store the backstage, query information and data.

The relationship between each subsystem is shown in figure 1 . 


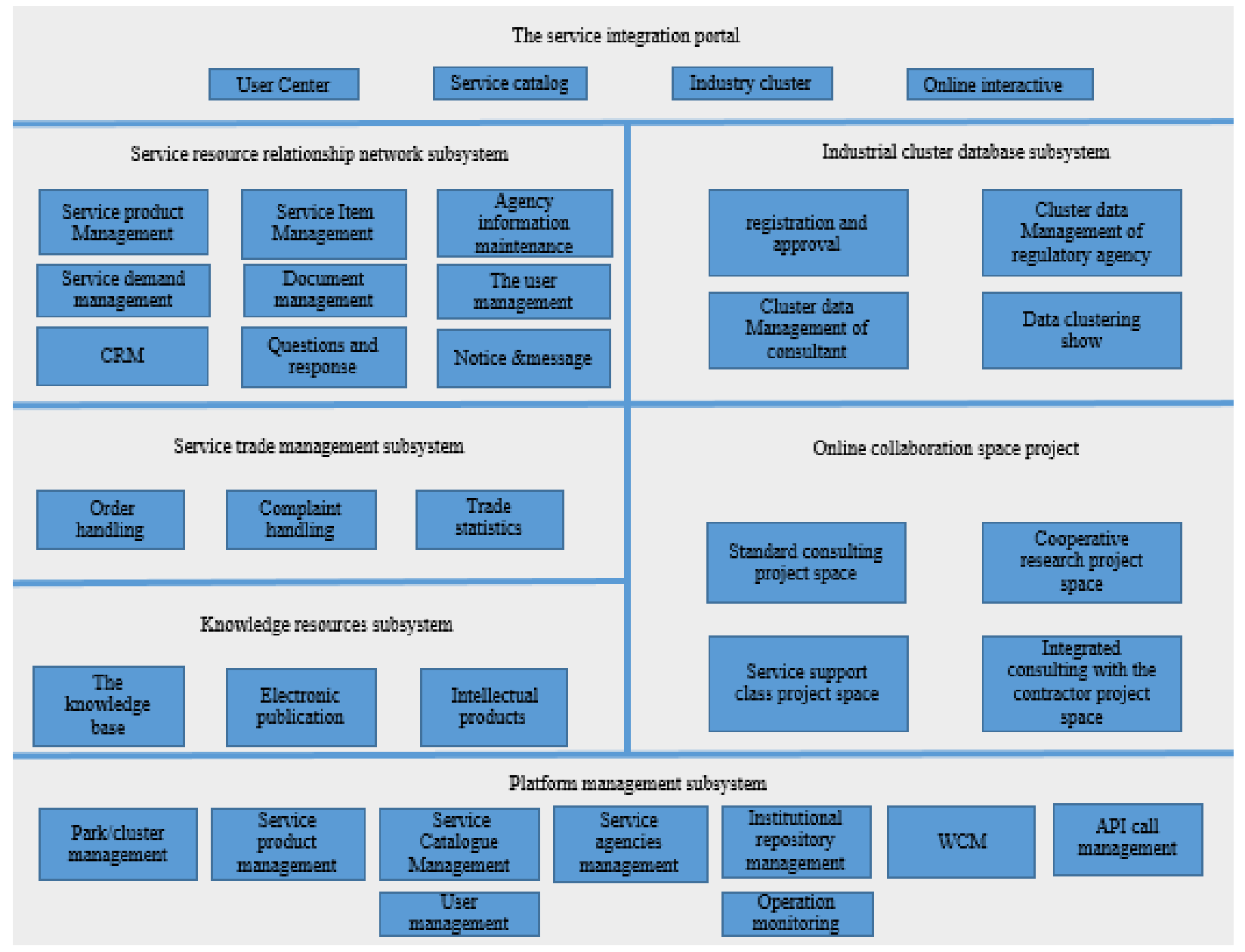

FIGURE 1 The relationship between each subsystem

\section{Conclusion}

No matter the public technology service platform, website group, or the new science and technology service forms, what's their core of the construction of the platform framework. Think carefully, their crucial question is all about how to effectively realize the exchange between different classes of data and resources, and user's interaction. The different understanding of the problem determines the construction scheme of the platform, there are three main views(1) Public science and technology service platform Shanghai research and development public service platform has put forward the mechanism characterized by sharing as the kernel of system[2];(2)Site groups - government website group, solve the problem of data exchange and connectivity between homogeneous and heterogeneous ,at the same time closely combined with the user[3];(3)New technology services formats - Analysis International, based on the mass of structured industry information and provide service through the content services and reading interaction.

So, how the public service platform representing three different service mode and the construction of the platform bring enlightenment to the construction of high-tech science and technology service integration platform? I think there are mainly the following several aspects of the enlightenment:

The first one is the openness of the science and technology service integration platform. The science and technology service is a complex process, specifically refers to the human input, time, equipment, production of natural resources, human resources, social resources and any other process combined with many other resources. In general, the closer the service product market science and technology to the market, the more commercialization and the more the need to extend the service scope, and look for a broader and deeper cooperation partners; And service integration platform of science and technology will need to open and provide a common platform for each enterprise, service agencies, government and any other open service resources in the industry cluster in order to realize resources' sharing and exchange;

The second is the service of the technology service integration platform. Science and technology service integration platform is a system integrated a variety of science and technology services, with more professional platform for docking, this can satisfy the demand of different areas, different levels and different stages. To the traditional offline 
contact, we can find a way to turn the offline cooperation into online services, truly provide convenient services - the sharing information and source for the enterprise and service agencies.

The third is the cooperativity of the technology and service integration platform. According to the scale economy theory, the economies of scale refers to the reasons of raising the level of specialization of production which makes the decline in the cost per unit, thus forming the decreasing economics as with the increasing of the enterprise's long-run average cost. The theory of scale economies, together with the unification of the resource management which can improve the focus of science and technology resources, these two can reduce the construction of the platform, the use and management of the cost, greatly improve the efficiency of transformation of scientific and technological resources.

\section{References}

[1] Chen Si. Whether the Gathering effect exists_-Empirical research based on China's high technology industry. China High-Tech Enterprises, 2011, (12):11-12.

[2] Li Xiaoxian, Liu Jie. Research on the Synergetic Mechanism of the Subsystems of Shanghai R\&D Public Service Platform [J]. Science of Science and Management of S \& T., 2006, (10):31-34.

[3] Ma Weishan, Li Bing, Tang Weiqing. Study and Design the Framework of Government Portal Group. Computer \& Digital Engineering, 2009, (9):139-142.

[4] Gui Ping. The public service platform of science and technology research both at home and abroad. Science and Technology Management Research, 2008, (7): 103-104.

[5] Liu Shijing. China industry cluster development report (2007-2008). Beijing: China Development Press, 2008.

[6] Li Jianbiao, Chen Guanyu, Xu Sai, Wang Minda. A Comparative Study of Urban Technology Service Industry between China and Developed Countries. Urban Insight, 2010, (6): 150-160. 